Prog Mol Biol Transl Sci. 2010 ; 96: 157-173. doi:10.1016/B978-0-12-381280-3.00007-5.

\title{
The Intestinal Stem Cell
}

Luis A. Chia, B.A. and Calvin J. Kuo, M.D., Ph.D.

Department of Medicine, Hematology Division, Stanford University School of Medicine CCSR 3100, 269 Campus Drive, Stanford, CA 94305 USA

\section{Introduction}

The adult intestinal epithelium has a well-defined organizational structure that can be divided into a functional (villus) and proliferative (crypt) region that is comprised of differentiated and undifferentiated cells, respectively. It is one of the most rapidly proliferating organs and complete turnover of the epithelium occurs every 3-5 days in an orderly fashion along the crypt-villus axis. This process is ultimately sustained by a small population of crypt-residing intestinal stem cells (ISCs) that give rise to a pool of multipotent progenitors, which do not differentiate immediately, but instead rapidly proliferate to create a pool of transit amplifying (TA) cells. These TA cells occupy the crypt length and subsequently give rise to the differentiated lineages of the intestine: the absorptive enterocytes, the mucin secreting goblet cells, the peptide hormone secreting enteroendocrine cells, the Paneth cells, M cells, tuft cells, and cup cells.

The intestinal crypts are enclosed within a fenestrated sheath of intestinal subepithelial myofibroblasts (ISEMFs) that have features of both fibroblasts and smooth muscle cells. Originally, these ISEMFs were largely thought of as a sheath of fibroblasts that were denser near the crypts than at the surface of the colon or in the villi of the intestine. However, it is now clear that they exist as a syncytium that extends throughout the lamina propia where it merges with the pericytes of the blood vessels that are found throughout the tissue. ISEMFs are a-smooth muscle actin (a-SMA) positive and can be distinguished from the a-SMApositive smooth muscle of the muscularis mucosa by their negative staining for desmin.

The development of the intestinal mucosa largely takes place in two broad steps: 1) organogenesis, during which interactions between the embryonic endoderm and mesoderm lead to the formation of the forgut, midgut, and hindgut; and 2) cytodifferentiation, in which the ISCs proliferate and differentiate into the four lineages of the intestinal epithelium. Both of these processes are complex, and there is accumulating evidence that the ISEMFs, as well as the epithelium, play an active role in the development of the intestinal mucosa.

Until recently, progress in understanding how the ISCs are maintained and regulated has been hampered by the lack of definitive ISC markers and in vitro culture methodologies. Despite this, work in the last 40 to 50 years has made significant headway in terms of identifying the actual ISCs and yielded many insights into how the ISCs are maintained and 
regulated by their surrounding niche. In fact, the recent identification of genes that functionally mark ISCs and the development of robust tissue culture methodologies has allowed for the emergence of evidence that challenges established paradigms regarding ISC maintenance and regulation. Here, we review the evidence demonstrating that ISCs generate all of the gastrointestinal epithelial cell lineages. We also examine the body of data regarding the precise identity and location of the ISCs, the role of the surrounding niche in ISC maintenance and regulation, as well as the hypothesis that the ISCs are the cell of origin in colorectal cancer.

\section{Monoclonality of Intestinal Crypts}

Numerous experiments in both mice and humans have shown that intestinal crypts are clonal populations, which are ultimately derived during development from a single cell. By using mice heterozygous for a defective glucose-6-phosphate dehydrogenase (G6pd) gene, Griffiths et al. demonstrated that the colonic crypts from adult mice were monoclonal. They showed that when compared to intestine from mice homozygous for the defective G6pd gene, which uniformly expressed low enzyme activity, heterozygous mice had large patches of intestine with high and low enzyme activity. Since they found no crypts that exhibited mixed enzyme activity, these results indicated that all epithelial cells in a crypt were derived from a single cell (Griffiths et al., 1988).

Similarly, Bjerknes and Cheng also confirmed the clonality of crypts by using somatic mutagenesis following the treatment of mice with $\mathrm{N}$-nitroso-N-ethylurea. Specifically, Nnitroso-N-ethylurea induces the random expression of Dolichos biflorus agglutinin (DBA) binding sites on mutated cells and allows for the binding of lectin. In these studies, mutated long-lived cells gave rise to ribbons of lectin-positive cells that migrated up the villus. Some ribbons contained all of the differentiated lineages of the epithelium, suggesting that these cells originated from mutated intestinal stem cells. However, some ribbons only contained columnar or mucinous cells, indicating that these cells originated from committed progenitors (Bjerknes and Cheng, 1999). Together, these findings support the existence of a hierarchy of pluripotent and committed progenitors within the intestinal crypt.

As in the mouse, analysis of intestinal tissues from an $\mathrm{XO} / \mathrm{XY}$ mosaic individual of male phenotype by nonisotopic in situ hybridization showed that human intestinal crypts were also clonal. In other words, the crypts from the $\mathrm{XO} / \mathrm{XY}$ individual were composed almost exclusively of either XY or XO cells. Indeed, the examination of crypts at patch borders revealed no mixed XO/XY crypts (Novelli et al., 1996). Thus, the evidence implies that both mouse and human crypts are clonal populations. However, these conclusions are only fitting for adult animals since intestinal crypts from neonatal mice have been found to be polyclonal (Schmidt et al., 1988). In other words, they show a mixed phenotype, but become monophenotypic within 2 weeks through a process of crypt purification, though the precise mechanisms regulating this process are still unclear.

Importantly, the establishment that crypts are clonal does not imply that crypts only contain a single stem cell. In fact, the precise number of stem cells per crypt and what controls their numbers is heavily debated. For example, it has been suggested that as many as 4-16 actual 
stem cells and 30-40 potential stem cells may exist in the small intestinal crypt (Potten and Loeffler, 1990). In contrast, colonic crypts may only contain as few as three or four actual stem cells.

\section{The Identity and Localization of Intestinal Stem Cells}

Despite a lack of distinctive ISC markers, it was realized early on that ISCs must locate to specific sites, such as the origin of cell efflux. Since the intestinal epithelium is divided into discrete units of proliferation (crypts) and differentiation (villi), and because migration begins at the base of the crypt, it was believed that basal crypt cells, or a subset thereof, were candidate ISCs. In 1974, Cheng and Leblond demonstrated in a series of landmark papers that the four differentiated lineages of the adult intestinal epithelium originated from cells that are located between and immediately above the Paneth cells, which they named cryptbase columnar (CBC) cells. After injecting mice with ${ }^{3} \mathrm{H}$-thymidine $\left(\left[{ }^{3} \mathrm{H}\right] \mathrm{dT}\right)$, which becomes incorporated with the DNA of replicating cells and induces local irradiation; Cheng and Leblond observed that some CBC cells phagocytosed neighboring cells (Cheng, 1974a; Cheng, 1974b; Cheng and Leblond, 1974a; Cheng and Leblond, 1974b; Cheng and Leblond, 1974c). As a result, these CBC cells subsequently contained phagosomes that were then used as a cytosolic marker to follow their evolution. The subsequent identification of phagocytic fragments in all four differentiated lineages supported their common origin as well as the Unitarian theory of epithelial cell formation in the mouse intestine. Notably, this hypothesis agreed with the hierarchical organization of cell populations in other tissues, such as the hematopoeitic system.

At the time however, the data supporting this hypothesis was equivocal. For example, data presented actually showed that more cell death occurred at cell positions 4-6 than at the crypt base, which was consistent with observations in crypts from mice that were externally irradiated. However, the recent identification of the leucine-rich $\mathrm{G}$ protein-coupled receptor 5 (Lgr5), a Wnt target gene that encodes an orphan $\mathrm{G}$ protein coupled receptor of unknown function, as a putative marker of ISCs strengthened the hypothesis that CBC cells were the actual stem cells of the intestinal epithelium. These cycling cells are located between the Paneth cells in the crypt bases, have been convincingly shown to mark cells that give rise to the four differentiated lineages of the intestinal epithelium, and possess the ability to regenerate the intestinal epithelium for extended periods of time (>12 months) (Barker et al., 2007). Recently, Sato and Clevers demonstrated that over a two-week period, single Lgr5positive cells can be cultured, undergo proliferation and crypt fission, and produce organoids that contain several crypt-like structures when supplemented with numerous growth factors including the Wnt agonist R-spondin1, EGF, Jagged peptide, and Noggin (Sato et al., 2009). One interpretation of these results is that the proliferation and organization of the Lgr5positive-derived organoids does not require the presence of a mesenchymal niche and potentially suggests the presence of an epithelial niche for the ISCs. However, it is also possible that the numerous supplementary factors in the Sato cultures, which regulate the Wnt, Notch, and BMP pathways, mimic signals presented by the mesenchyme. Further, the growth of Sato cultures in matrigel, which contains laminin, collagen IV, EGF, insulin-like growth factor, tissue plasminogen activator, as well as TGF- $\beta$, all of which are expressed by 
myofibroblasts, also suggests that although the physical presence of mesenchymal niche cells may not be required, their secretory components may be necessary.

At the same time, there is growing evidence that cells at cell position ${ }^{+} 4$ from the crypt base (defined as ${ }^{+}$) are also putative ISCs. In 1975, Cairns first proposed the immortal strand hypothesis in which stem cells repeatedly segregate their chromosomes asymmetrically (Cairns, 1975). It was argued that such a mechanism would have evolved to minimize the risk of incurring DNA replication-induced errors in cells that are long lived, since such mutations would be passed on to daughter cells that would terminally differentiate. The inability of cells at cell position 4-5 to retain $\left[{ }^{3} \mathrm{H}\right] \mathrm{dT}$ or bromodeoxyuridine (BrdU) label through many rounds of division (10-15) during normal homeostasis, and the ability to generate label-retaining cells (LRCs) when mice were exposed to label while making new stem cells, lends support to the immortal strand hypothesis and suggests that a population of ${ }^{+} 4$ cells are the actual ISCs (Cairns, 2006). In fact, in double label experiments, it was shown that $\left[{ }^{3} \mathrm{H}\right] \mathrm{dT}$-LRCs have the ability to incorporate BrdU (Potten et al., 2002). Analysis of such double-labeled cells showed that both labels were differentially segregated.

Specifically, BrdU disappeared from the LRCs after the second round of cell division, while the $\left[{ }^{3} \mathrm{H}\right] \mathrm{dT}$ persisted through many rounds of cell division. Of note, whereas these LRCs were found most frequently at the ${ }^{+} 4$ region, they in fact consisted of cells located between the Paneth cells and as high as 10-12 cell positions above the crypt base. Recently, the identification of Bmi1, a member of the polycomb family of transcriptional repressors, as a marker of ISCs further strengthened the notion that cells at the ${ }^{+} 4$ position are also the actual stem cells of the small intestine. Bmi $1^{+}$cells primarily localize to the ${ }^{+} 4$ position and have the ability to expand, self-renew, and give rise to all of the differentiate lineages of the small intestine (Sangiorgi and Capecchi, 2008).

At the moment, it is currently unknown whether $\mathrm{Bmi1} 1^{+}$cells give rise to $\mathrm{Lgr}^{+}$or vice versa. One possibility is that Lgr5 and Bmi1 identify two distinct populations of ISCs. The distinct expression pattern of these two genes certainly supports this hypothesis; Lgr5 is expressed throughout the small and large intestine (Barker et al., 2007), while Bmil expression is restricted to the proximal small intestine (Sangiorgi and Capecchi, 2008). Moreover, emerging evidence reveals that both quiescent and active stem cell subpopulations may coexist within a tissue ( $\mathrm{Li}$ and Clevers). For example, in the hair follicle, CD $34^{+}$LRC bulge cells have been functionally defined as hair follicle stem cells by their ability to reconstitute the entire hair follicle (Blanpain et al., 2004; Tumbar et al., 2004). These CD $34^{+}$LRCs retain label for many months, suggesting that they exist in a quiescent state and are not actively involved in hair regeneration (Waghmare et al., 2008). Recently, it was shown that these bulge stem cells do not directly generate transitamplifying cells, but rather give rise to an intermediate stem cell population located at the hair germ, which expresses Lgr5, is actively cycling, and can also reconstitute the entire hair follicle (Jaks et al., 2008; Zhang et al., 2009). These findings demonstrate that the hair follicle contains both quiescent and actively cycling populations of stem cells that reside in separate yet adjacent locations. Studies of HSC also demonstrate that both active and quiescent populations exist in the hematopoietic system (Tumbar et al., 2004; Wilson et al., 2008). Thus, it is possible that $\mathrm{Bmil}^{+}$cells, though unknown whether they can retain label, 
and $\operatorname{Lgr}^{+}$cells represent quiescent and actively cycling ISCs, respectively. Clearly, the relationship between these two cell populations requires further investigation.

\section{Other Putative Intestinal Stem Cell Markers}

Musashi-1 (Msi-1) was proposed as a putative ISC marker prior to the identification of Lgr5 and Bmil as bona fide stem cell markers. Msi-1 encodes an RNA-binding protein that was initially found to be associated with early asymmetric division in sensory organ precursor cells in Drosophila and is believed to modulate Notch signaling by suppressing the expression of Numb mRNA synthesis (Imai et al., 2001; Nakamura et al., 1994). Analysis of Msi-1 protein expression by immunohistochemistry revealed that a small number of cells at cell position 4-5 in the adult small intestine and a few cells at the base of the crypt in the large intestine were positive for Msi-1 (Potten et al., 2003). Additionally, strong Msi-1 expression was observed in developing crypts, post-irradiation regenerating crypts, and in early adenomas (Potten et al., 2003). Together these data suggested that Msi-1 could mark ISCs. However, the ability of these Msi-1 cells to give rise to all of the differentiated lineages of the intestine has not yet been demonstrated.

Likewise, the microtubule-associated kinase DCAMKL-1 (Doublecortin and CaM Kinaselike1) was also proposed as a candidate ISC marker (May et al., 2008). DCAMKL-1 is expressed in cells near position 4 in normal intestinal crypts, and these cells were found to be Msi-1 positive (Potten et al., 2003). DCAMKL-1 ${ }^{+}$crypt epithelial cells were shown to retain BrdU in a modified label retention assay. One group even demonstrated the ability of these cells to self-renew and form spheroids in suspension culture (May et al., 2009). However, robust lineage tracing experiments have not been performed and it remains unclear whether these cells can give rise to all of the differentiated lineages of the intestinal epithelium.

Another putative ISC marker is mouse telomerase reverse transcriptase (mTert), which is a gene that is downregulated upon differentiation in most somatic cells. In the intestine, the analysis of mTert-GFP mice showed that GFP specifically marks long-term BrdU-retaining intestinal crypt cells (Breault et al., 2008). Though its ability to functionally mark ISCs has not yet been determined, the availability of the mTert-GFP mice and methodology to culture single ISCs via the Sato method, suggests that $\mathrm{mTert}^{+}$ISCs can be prospectively isolated and assayed for its stem cell activity in vitro.

Other putative ISC markers include: BMPR1A, phosphorylated-PTEN, phosphorylated- $\beta$ catenin, Wip1 phosphatase, phosphorylated-Akt, Apex1, Diap3, Gemin4, Rhobtb3, and and Wdrl2 (Scoville et al., 2008). Whether these genes mark ISCs that can give rise to all of the differentiated lineages of the intestine requires further investigation. Importantly, the lineage tracing methodologies used to identify Lgr5 as a stem cell marker, have enabled the identification of additional markers such as Olmf4 and Ascl2 (van der Flier et al., 2009), though these markers have not been themselves confirmed through lineage tracing studies. Regardless, the association of the expression of these genes with ${ }^{+} 4$ cells or cells in the lower regions of the crypt have yielded some interesting insights. 
For example, the Wnt target Achaete scute-like 2 (Ascl2) controls the fate of $\mathrm{Lgr5}^{+}$ISCs. Specifically, conditional deletion of Ascl2 in the adult small intestine induces the disappearance of the Lgr5 ${ }^{+}$ISCs. Accordingly, the transgenic overexpression of Ascl2 throughout the intestinal epithelium induces crypt hyperplasia, as well as the appearance of ectopic crypt like structures in the villi (van der Flier et al., 2009). These reports are in accordance with findings about the importance of Wnt signaling in maintaining the ISC niche and the ISCs.

\section{The Intestinal Stem Cell Niche}

In 1978, Schofield introduced the idea of a stem cell niche when he proposed a hypothesis in which hematopoietic stem cells (HSCs) are seen in association with other cells, which confer HSCs with their stem cell-like behavior. Schofield initially described the stem cell as a fixed tissue cell, whose maturation and continued proliferation as a stem cell is respectively prevented and assured (Schofield, 1978). According to this hypothesis, the progeny of HSCs that do not occupy a similar stem cell niche are considered first generation colony-forming cells that proliferate, mature, and differentiate.

In the intestine, the stem cell niche is likely comprised of epithelial, subepithelial, and luminal components. Mucosal constituents include the permeable basement membrane and the cells that are located beneath it, such as mesenchymal cells (myofibroblasts, fibroblasts and smooth muscle cells), endothelial cells, neural cells, and immune cells. All of these cells may regulate the function of stem cells via secreted proteins or their direct interaction with the stem cells themselves. For example, it is known that Wnt signaling is important for the maintenance of the intestinal stem cells and that the epithelial and mesenchymal cells differentially express specific components of the Wnt signaling pathway, suggesting that mesenchymal-epithelial crosstalk is required for the maintenance of the intestine (Gregorieff et al., 2005; Korinek et al., 1998; Kuhnert et al., 2004). On the other hand, the niche may also be comprised of luminal components, which may be derived from epithelial cells or from the large number of bacteria present in the lumen. For example, the mucin glycoprotein Muc2 appears to play a crucial role in stem cell maintenance as Muc2-deficient mice have been reported to exhibit aberrant crypt morphology and altered cell maturation and migration (Velcich et al., 2002).

Though considerable knowledge about the niche has been gained in the past few years, the precise components of the niche largely remain unknown because the identification and exact location of the intestinal stem cell is still under intense investigation. Still it has emerged that several signaling pathways likely play a role in the maintenance and regulation of the ISCs and their differentiated progeny, such as the Wnt, Notch, BMP, Hh, and EGFR signaling pathways.

\section{Wnt Signaling}

The Wnt signaling pathway is critical during embryonic development and organogenesis in many species. Wnts are evolutionarily conserved, cysteine-rich glycoproteins that signal in both a paracrine and autocrine fashion. There are 19 known murine Wnt genes, which bind to the seven-pass transmembrane protein receptors of the frizzled (Fz) family, 10 of which 
have been identified in mice, and to the single-span low-density lipoprotein receptor-related proteins (LRP). When the Wnt ligand binds to the Fz/LRP complex, this triggers the release of $\beta$-catenin from a so-called "destruction complex," which is comprised of glycogen synthase kinase 3- $\beta$ (GSK3- $\beta$ ), axin, and the adenomatous polyposis coli (APC) tumorsuppressor protein. The free $\beta$-catenin then accumulates and translocates to the nucleus, where it associates with DNA-binding factors of the T-cell factor/lymphocyte enhancer factor (TCF/LEF) family to activate the transcription of target genes including c-myc, cyclin D1, CD44, c-Jun, and Lgr5. Importantly, Wnts also stimulate cellular responses independently of $\beta$-catenin and TCF through the so-called non-canonical pathway, which involves the intracellular release of $\mathrm{Ca}_{2}^{+}$and/or the planar polarity pathway.

Previous studies have demonstrated the importance of the Wnt signaling pathway in the maintenance of the proliferative compartment of the intestinal epithelium. For example, the systemic expression of Dkk1, a Wnt inhibitor, by adenoviral infection results in crypt loss and the subsequent degeneration of the intestinal epithelium (Kuhnert et al., 2004).

Likewise, transgenic expression of Dkk1 under the control of the villin promoter or (Pinto et al., 2003) disruption of Tcf712 (Tcf4), a downstream effector of Wnt signaling, in mice, specifically depletes the epithelial stem cell compartment of the small intestine without disrupting the induction of epithelial cells from endoderm, as demonstrated by the presence of differentiated enterocytes and goblet cells in Tcf712 ${ }^{-/-}$embryos (Korinek et al., 1998). In colorectal cancer cells, disruption of $\beta$-catenin/TCF signaling results in rapid cell cycle arrest. Furthermore, induced deletion of the Wnt target gene c-myc in adult mice results in rapid loss of intestinal crypts (Muncan et al., 2006). Accordingly, the injection of human Rspondin 1, a Wnt agonist, into mice results in the rapid onset of crypt cell proliferation that is accompanied by $\beta$-catenin stabilization, as well as increases in the number of crypt based columnar cells in the crypts (unpublished results). These data suggest that Wnt signaling is required for the maintenance of ISCs.

In addition to maintaining homeostasis, the Wnt signaling pathway also plays a key role in malignant transformation. Mutations of the APC tumor suppressor gene are found in approximately $60-80 \%$ of human sporadic colorectal tumors (Miyaki et al., 1994; Smith et al., 1993). This mutation inhibits the cytosolic degradation of $\beta$-catenin by the GSK3- $\beta$ / axin/APC destruction complex, which results in the accumulation of nuclear $\beta$-catenin and the subsequent upregulation of pro-proliferation genes that are induced by TCF/LEF transcription.

\section{Notch signaling}

In other systems, the Notch signaling pathway has been shown to be crucial in regulating cell fate decisions. In the intestine, Notch receptors, the ligand Delta, and the associated Hes transcription factors are chiefly expressed at the base of the intestinal crypts. The Notch genes encode transmembrane receptors that interact with ligands, which are also transmembrane proteins that are located on adjacent cells. In vertebrates, there are four receptors and five ligands. Receptor-ligand interaction results in cleavage of the intracellular domain of the Notch receptor, its transduction to the nucleus, and transcriptional activation. It is believed that the cell contact dependent nature of Notch signaling enables the 
coordination of proliferative/differentiative decisions and cell fates in a group of otherwise uncommitted cells.

In the intestine, maintenance of the proliferative compartment requires the constitutive activation of the Notch signaling cascade. Inhibition of the pathway by the conditional inactivation of the downstream transcription factor CSL/RBP-J or the injection of a $\gamma$ secretase inhibitor, results in the massive conversion of proliferative crypts into post-mitotic goblet cells (van Es et al., 2005). Accordingly, the requirement for Notch signaling in the maintenance of stem cell proliferation during intestinal tumorigenesis was also demonstrated; $\gamma$-secretase inhibition in $\mathrm{Apc}^{\mathrm{Min}}$ mice caused widespread Goblet cell conversion within adenomas (van Es et al., 2005).

Furthermore, the analysis of mice deficient for the basic helix-loop-helix proteins Hes-1, Math-1, and neurogenin-3, all of which are transcriptional targets of Notch signaling in other tissues, have indirectly implicated the Notch signaling pathway in the regulation of the earliest intestinal cell fate decisions (Jenny et al., 2002; Jensen et al., 2000; Yang et al., 2001). For example, deletion of Math-1 results in the absence of goblet, Paneth, and enteroendocrine cell lineages, with enterocytes being the only differentiated cell type in the murine small intestine (Shroyer et al., 2007).

\section{BMP Signaling}

Bone morphogenetic proteins (BMPs) belong to the transforming growth- $\beta$ superfamily of proteins whose signaling is initiated by binding to BMP receptor types I or II (BMPR1 or BMPR2). This interaction leads to the phosphorylation of SMAD1, 5, or 8, which heterodimerizes with SMAD4, translocating to the nucleus where they act as transcriptional activators. Active BMP signaling, as indicated by the presence of phosphorylated SMADs, is found predominantly in differentiated intestinal epithelial cells. Accordingly, expression of BMPs is highest at the top of intestinal crypts, whereas BMP antagonists, such as Gremlin 1 and 2 and Noggin, are most strongly expressed at the crypt base.

BMPs appear to antagonize Wnt signaling, via the PTEN tumor-suppressor protein, and so permit and restrict differentiation and proliferation, respectively. Conditional mutation of BMPR1A resulted in de novo crypt formation and a juvenile polyposis phenotype (He et al., 2004). Correspondingly, there was also reduced differentiation of the intestinal epithelium. As expected, inhibition of BMP signaling by conditional ectopic expression of the BMPantagonist Noggin also increased proliferation, and led to de novo crypt formation and polyposis (Haramis et al., 2004).

Likewise, Gremlin 1, a BMP antagonist, was shown to partially inhibit cell differentiation in vitro and promote proliferation. Consistent with these observations, stimulation of colon cancer cell lines by BMP2, a BMP agonist, inhibited growth (Beck et al., 2006; Kosinski et al., 2007). 


\section{Hedgehog signaling}

The hedgehog (Hh) signaling pathway has also been implicated in the maintenance of the intestinal epithelium. Mice deficient in Sonic (Shh) or Indian (Ihh) hedgehog exhibit intestinal abnormalities. For example, $\mathrm{Ihh}^{-/-}$mice die perinatally and exhibit reduced proliferation in the intervillus region as well as a depleted progenitor cell compartment, suggesting that Ihh is important in the maintenance of ISCs. In contrast, $\mathrm{Shh}^{-/-}$mice display overgrown duodenal villi and stomach epithelium. These findings suggest that Shh may inhibit rather than stimulate proliferation in these regions. Nonetheless, both models exhibit reduced smooth muscle, suggesting that Shh and Ihh have partially redundant functions (Ramalho-Santos et al., 2000). Of note, unlike the other previously described pathways, the direction of hedgehog signaling is reversed. In the intestine, both Sonic (Shh) and Indian (Ihh) hedgehog are initially expressed throughout the intestinal epithelium. After villus formation, both proteins are redistributed becoming concentrated in the epithelial cells of the intervillus region. By using villin-Hhip mice, transgenic mice expressing the pan-hedgehog inhibitor, Hhip (hedgehog interacting protein), under the control of the villin promoter, Madison et al. showed that Hedgehog signaling occurs in a paracrine fashion from the epithelium to the Ptch1-expressing ISEMFs and smooth muscle cells (Madison et al., 2005). Consequently, Hh signaling is not directly involved in the fate of the epithelial cells but is important in the overall organization of the crypts and villi of the intestinal mucosa. Moreover, it has been demonstrated that Hh signaling is an antagonist of Wnt signaling, as the transfection of Indian hedgehog and TCF4 resulted in the downregulation of TCF4 and restoration of Ihh, respectively (van den Brink, 2004). Thus, it appears that hedgehog signaling functions to restrict Wnt signaling to the crypt base allowing for the indirect regulation of the ISCs.

\section{Epidermal Growth Factor Signaling}

EGFR appears to be required for epithelial homeostasis in the mouse GI tract, and EGFR ligands are required for the development and maintenance of the intestine. For example, mice lacking functional EGFR have been shown to develop disorganized crypts (Threadgill et al., 1995). In Drosophila, inactivation of EGFR inhibits the growth and division of ISCs (Jiang and Edgar, 2009). These studies demonstrate the essential role that EGFR signaling plays in intestinal homeostasis. Interestingly, genetic studies have shown that ectopic activation of the EGFR pathway can accelerate tumor progression in the APC $\mathrm{min} /+$ background (Bilger et al., 2008; Haigis et al., 2008; Janssen et al., 2006). Accordingly, partial loss of function of EGFR has also been reported to significantly reduce adenoma formation in $\mathrm{Apc}^{\mathrm{min} /+}$ mice (Roberts et al., 2002). Furthermore, antibodies targeting EGFR have also been shown to be effective in treating colorectal cancer provided there are no activating mutations in downstream signaling components, such as KRAS or BRAF (Amado et al., 2008; Di Nicolantonio et al., 2008).

\section{Evidence for a Non-mesenchymal Niche}

A model whereby stem cells receive signals from a mesenchymal niche and a stem cell migrates away from its niche to differentiate appears to hold true in the hematopoietic and 
hair follicle system. However, in the intestine, emerging evidence suggests that novel mechanisms may exist for ISC regulation.

Work in Drosophila has revealed for example, that ISCs actively select the fate of their progeny independently of a detectable stem cell niche. In this model, the selective expression of the Notch ligand Delta, by the ISCs, functions to activate Notch signaling in adjacent daughter cells to determine cell fate (Ohlstein and Spradling, 2007). In fact, studies have indicated that during intestinal organogenesis, a founder adult midgut progenitor (AMP) undergoes asymmetric division and signals via the Notch signaling pathway to direct its first daughter cell to become a peripheral cell, which then act as a niche for AMPs to keep them undifferentiated until metamorphosis. During metamorphosis, the peripheral cells break down and allow the AMPs to respond to Notch signaling and differentiate into the differentiated lineages of the intestinal epithelium (Mathur et al.).

Accordingly, studies have shown that the Drosophila EGFR pathway is essential for ISC proliferation during both normal midgut homeostasis and regeneration after damage. The analysis of EGFR ligand expression demonstrated that the EGFR ligand $V n$ was expressed in the visceral muscle during gut regeneration, suggesting that the visceral muscle might serve as part of the ISC niche. However, the specific downregulation of $V n$ in the visceral muscle did not affect ISC proliferation, demonstrating that visceral muscle-derived $V n$ is probably not essential for the maintenance of ISCs (Jiang and Edgar, 2009). Interestingly, the expression of Spi and Krn, two other EGFR ligands, in midgut epithelial cells suggests that these epithelial-derived EGFR ligands may be responsible for activating EGFR signaling in the ISCs. Together these findings support the hypothesis that the epithelium itself may represent a critical component of the ISC niche.

Therefore, it is tempting to speculate that epithelial cell types may be a critical component of the mouse intestinal niche. In murine small intestine, Paneth cells have been shown to specifically secrete the canonical Wnt ligands, Wnt-3 and Wnt-9b (Gregorieff et al., 2005). Since nuclear $\beta$-catenin is observed in Paneth cells, it is possible that these Wnts operate in an autocrine fashion to induce canonical Wnt signaling or signal to nearby ISC or progenitors to drive their proliferation. However, such signals originating from Paneth cells or other epithelial cell types may be important but not sufficient for intestinal growth, since pure epithelial intestinal cultures appear to absolutely require exogenous growth factor supplementation (R-spondin1, EGF, Noggin, and Jagged) (Sato et al., 2009) which may reflect signals either provided in vivo by the mesenchyme, or present endogenously in explant cultures that contain mesenchymal elements (Ootani et al., 2009).

\section{Intestinal Stem Cells as the Cell of Origin of Colorectal Cancer}

The self-renewing capabilities of stem cells may be relevant to cancer whereby tumors may initiate from a small subpopulation of cells, which possesses the bulk of long-term proliferative activity. The examination of adenomas from XO/XY patients with FAP showed that $76 \%$ of adenomas were polyclonal (Novelli et al., 1996). This was despite observations that monocryptal adenomas showed either the XO or XY genotype, and no mixed XO/XY genotype. One possible explanation is that $\mathrm{XO} / \mathrm{XY}$ adenomas may actually be $\mathrm{XY}$ adenomas 
that have focally lost their $\mathrm{Y}$ chromosome. For example, it is known that the $\mathrm{Y}$ chromosome is often lost in a variety of carcinomas, although this usually occurs after P53 loss, or during late stages of adenoma development in the intestine. Another possible explanation is that random collisions occur between independently transformed neighboring crypts. However, it appears that neither of these explanations can account for the high proportion of polyclonality that is observed in these patients.

Regardless, there is accumulating evidence that the earliest lesion in colorectal tumorigenesis occurs in the stem cells. Recently, Barker et al. showed that the deletion of APC in $\mathrm{Lgr}^{+}$cells leads to the transformation of epithelial cells within days (Barker et al., 2009). These transformed $\mathrm{Lgr}^{+}$cells rapidly generate microadenomas, which exhibit unimpeded growth, and develop into macroscopic adenomas within 3-5 weeks. In contrast, the deletion of APC in short-lived transit-amplifying cells results in stalled growth of the induced microadenomas. In these mice, even after 30 weeks, few large adenomas were observed. Furthermore, although a direct comparison was not performed, Barker et al. also reported that the conditional activation of a $\beta$-catenin allele $(\operatorname{loxP}(\mathrm{ex} 3))$ in $\mathrm{Bmi}^{+}$cells also resulted in adenoma formation within 3-4 weeks after cre induction (Barker et al., 2009). In both cases, these observations support the hypothesis that the transformation of ISC constitutes the principal route towards intestinal cancer.

Moreover, other recent studies have also shown that cancer-initiating cells can be identified in colon carcinomas. By using renal capsule transplantation assays in NOD/SCID mice, O'Brien et al. found that a fraction of the $\mathrm{CD} 133^{+}$cells were able to maintain themselves as well as differentiate and re-establish tumor heterogeneity upon serial transplantation (O'Brien et al., 2007). Independently, Ricci-Vitiani et al. also established that CD133+ cancer cells could be subcutaneously injected into immunodeficient mice where they readily reproduced the original tumor (Ricci-Vitiani et al., 2007). Both studies demonstrated that CD133- cells did not form tumors. Together, these findings suggest that cancers themselves are maintained by a population of cancer cells, and there is accumulating evidence that tumorigenesis is initiated in the ISCs.

\section{Conclusion}

An increasing body of knowledge is accumulating regarding the biology of intestinal stem cells, aided by molecular isolation and lineage tracing techniques. It is now clear that single ISCs can indeed give rise to all of the differentiated lineages of the intestinal epithelium. Though the precise identity of the actual ISC is still debated, studies clearly demonstrate that the $\mathrm{Lgr}^{+} \mathrm{CBC}$ cells and the $\mathrm{Bmi1} 1^{+}$cells at cell position ${ }^{+} 4$ both have the ability to selfrenew, to undergo multi-lineage differentiation, and to initiate polyposis. However, many questions still remain unanswered, including the potential for distinct populations of ISCs, their functional interrelationships, the control of their numbers, and ultimate relevance to carcinogenesis and cancer stem cells/tumor-initiating cells. Similarly, the precise location and cellular composition of the niches in which ISCs reside remain to be elucidated, along with the relative contributions of mesenchymal versus epithelial niches. Regardless, better understanding of the physiological mechanisms that regulate stem cell maintenance potentially offers new strategies to promote tissue regeneration after injury, to maintain stem 
cell activity during aging, or to sensitize cancer stem cells to therapy. Clearly, translation of these basic biological discoveries will have many implications in the fields of stem cell biology, regenerative medicine, cancer, aging, and therapeutics.

\section{References}

Amado RG, Wolf M, Peeters M, Van Cutsem E, Siena S, Freeman DJ, Juan T, Sikorski R, Suggs S, Radinsky R, et al. Wild-type KRAS is required for panitumumab efficacy in patients with metastatic colorectal cancer. J Clin Oncol. 2008; 26:1626-1634. [PubMed: 18316791]

Barker N, Ridgway RA, van Es JH, van de Wetering M, Begthel H, van den Born M, Danenberg E, Clarke AR, Sansom OJ, Clevers H. Crypt stem cells as the cells-of-origin of intestinal cancer. Nature. 2009; 457:608-611. [PubMed: 19092804]

Barker N, van Es JH, Kuipers J, Kujala P, van den Born M, Cozijnsen M, Haegebarth A, Korving J, Begthel H, Peters PJ, Clevers H. Identification of stem cells in small intestine and colon by marker gene Lgr5. Nature. 2007; 449:1003-1007. [PubMed: 17934449]

Beck SE, Jung BH, Fiorino A, Gomez J, Rosario ED, Cabrera BL, Huang SC, Chow JY, Carethers JM. Bone morphogenetic protein signaling and growth suppression in colon cancer. Am J Physiol Gastrointest Liver Physiol. 2006; 291:G135-G145. [PubMed: 16769811]

Bilger A, Sullivan R, Prunuske AJ, Clipson L, Drinkwater NR, Dove WF. Widespread hyperplasia induced by transgenic TGFalpha in ApcMin mice is associated with only regional effects on tumorigenesis. Carcinogenesis. 2008; 29:1825-1830. [PubMed: 18310091]

Bjerknes M, Cheng H. Clonal analysis of mouse intestinal epithelial progenitors. Gastroenterology. 1999; 116:7-14. [PubMed: 9869596]

Blanpain C, Lowry WE, Geoghegan A, Polak L, Fuchs E. Self-renewal, multipotency, and the existence of two cell populations within an epithelial stem cell niche. Cell. 2004; 118:635-648. [PubMed: 15339667]

Breault DT, Min IM, Carlone DL, Farilla LG, Ambruzs DM, Henderson DE, Algra S, Montgomery RK, Wagers AJ, Hole N. Generation of mTert-GFP mice as a model to identify and study tissue progenitor cells. Proc Natl Acad Sci U S A. 2008; 105:10420-10425. [PubMed: 18650388]

Cairns J. Mutation selection and the natural history of cancer. Nature. 1975; 255:197-200. [PubMed: 1143315]

Cairns J. Cancer and the immortal strand hypothesis. Genetics. 2006; 174:1069-1072. [PubMed: 17121966]

Cheng H. Origin, differentiation and renewal of the four main epithelial cell types in the mouse small intestine. II. Mucous cells. Am J Anat. 1974a; 141:481-501. [PubMed: 4440633]

Cheng H. Origin, differentiation and renewal of the four main epithelial cell types in the mouse small intestine. IV. Paneth cells. Am J Anat. 1974b; 141:521-535. [PubMed: 4440634]

Cheng H, Leblond CP. Origin, differentiation and renewal of the four main epithelial cell types in the mouse small intestine. I. Columnar cell. Am J Anat. 1974a; 141:461-479. [PubMed: 4440632]

Cheng H, Leblond CP. Origin, differentiation and renewal of the four main epithelial cell types in the mouse small intestine. III. Entero-endocrine cells. Am J Anat. 1974b; 141:503-519. [PubMed: 4216261]

Cheng H, Leblond CP. Origin, differentiation and renewal of the four main epithelial cell types in the mouse small intestine. V. Unitarian Theory of the origin of the four epithelial cell types. Am J Anat. 1974c; 141:537-561. [PubMed: 4440635]

Di Nicolantonio F, Martini M, Molinari F, Sartore-Bianchi A, Arena S, Saletti P, De Dosso S, Mazzucchelli L, Frattini M, Siena S, Bardelli A. Wild-type BRAF is required for response to panitumumab or cetuximab in metastatic colorectal cancer. J Clin Oncol. 2008; 26:5705-5712. [PubMed: 19001320]

Gregorieff A, Pinto D, Begthel H, Destree O, Kielman M, Clevers H. Expression pattern of Wnt signaling components in the adult intestine. Gastroenterology. 2005; 129:626-638. [PubMed: 16083717] 
Griffiths DF, Davies SJ, Williams D, Williams GT, Williams ED. Demonstration of somatic mutation and colonic crypt clonality by X-linked enzyme histochemistry. Nature. 1988; 333:461-463. [PubMed: 3374587]

Haigis KM, Kendall KR, Wang Y, Cheung A, Haigis MC, Glickman JN, Niwa-Kawakita M, SweetCordero A, Sebolt-Leopold J, Shannon KM, et al. Differential effects of oncogenic K-Ras and NRas on proliferation, differentiation and tumor progression in the colon. Nat Genet. 2008; 40:600 608. [PubMed: 18372904]

Haramis AP, Begthel H, van den Born M, van Es J, Jonkheer S, Offerhaus GJ, Clevers H. De novo crypt formation and juvenile polyposis on BMP inhibition in mouse intestine. Science. 2004; 303:1684-1686. [PubMed: 15017003]

He XC, Zhang J, Tong WG, Tawfik O, Ross J, Scoville DH, Tian Q, Zeng X, He X, Wiedemann LM, et al. BMP signaling inhibits intestinal stem cell self-renewal through suppression of Wnt-betacatenin signaling. Nat Genet. 2004; 36:1117-1121. [PubMed: 15378062]

Imai T, Tokunaga A, Yoshida T, Hashimoto M, Mikoshiba K, Weinmaster G, Nakafuku M, Okano H. The neural RNA-binding protein Musashil translationally regulates mammalian numb gene expression by interacting with its mRNA. Mol Cell Biol. 2001; 21:3888-3900. [PubMed: 11359897]

Jaks V, Barker N, Kasper M, van Es JH, Snippert HJ, Clevers H, Toftgard R. Lgr5 marks cycling, yet long-lived, hair follicle stem cells. Nat Genet. 2008; 40:1291-1299. [PubMed: 18849992]

Janssen KP, Alberici P, Fsihi H, Gaspar C, Breukel C, Franken P, Rosty C, Abal M, El Marjou F, Smits R, et al. APC and oncogenic KRAS are synergistic in enhancing Wnt signaling in intestinal tumor formation and progression. Gastroenterology. 2006; 131:1096-1109. [PubMed: 17030180]

Jenny M, Uhl C, Roche C, Duluc I, Guillermin V, Guillemot F, Jensen J, Kedinger M, Gradwohl G. Neurogenin 3 is differentially required for endocrine cell fate specification in the intestinal and gastric epithelium. Embo J. 2002; 21:6338-6347. [PubMed: 12456641]

Jensen J, Pedersen EE, Galante P, Hald J, Heller RS, Ishibashi M, Kageyama R, Guillemot F, Serup P, Madsen OD. Control of endodermal endocrine development by Hes-1. Nat Genet. 2000; 24:36-44. [PubMed: 10615124]

Jiang H, Edgar BA. EGFR signaling regulates the proliferation of Drosophila adult midgut progenitors. Development. 2009; 136:483-493. [PubMed: 19141677]

Korinek V, Barker N, Moerer P, van Donselaar E, Huls G, Peters PJ, Clevers H. Depletion of epithelial stem-cell compartments in the small intestine of mice lacking Tcf-4. Nat Genet. 1998; 19:379_ 383. [PubMed: 9697701]

Kosinski C, Li VS, Chan AS, Zhang J, Ho C, Tsui WY, Chan TL, Mifflin RC, Powell DW, Yuen ST, et al. Gene expression patterns of human colon tops and basal crypts and BMP antagonists as intestinal stem cell niche factors. Proc Natl Acad Sci U S A. 2007; 104:15418-15423. [PubMed: 17881565]

Kuhnert F, Davis CR, Wang HT, Chu P, Lee M, Yuan J, Nusse R, Kuo CJ. Essential requirement for Wnt signaling in proliferation of adult small intestine and colon revealed by adenoviral expression of Dickkopf-1. Proc Natl Acad Sci U S A. 2004; 101:266-271. [PubMed: 14695885]

Li L, Clevers H. Coexistence of quiescent and active adult stem cells in mammals. Science. 327:542545. [PubMed: 20110496]

Madison BB, Braunstein K, Kuizon E, Portman K, Qiao XT, Gumucio DL. Epithelial hedgehog signals pattern the intestinal crypt-villus axis. Development. 2005; 132:279-289. [PubMed: 15590741]

Mathur D, Bost A, Driver I, Ohlstein B. A transient niche regulates the specification of Drosophila intestinal stem cells. Science. 327:210-213. [PubMed: 20056890]

May R, Riehl TE, Hunt C, Sureban SM, Anant S, Houchen CW. Identification of a novel putative gastrointestinal stem cell and adenoma stem cell marker, doublecortin and CaM kinase-like-1, following radiation injury and in adenomatous polyposis coli/multiple intestinal neoplasia mice. Stem Cells. 2008; 26:630-637. [PubMed: 18055444]

May R, Sureban SM, Hoang N, Riehl TE, Lightfoot SA, Ramanujam R, Wyche JH, Anant S, Houchen $\mathrm{CW}$. Doublecortin and CaM kinase-like-1 and leucine-rich-repeat-containing G-protein-coupled 
receptor mark quiescent and cycling intestinal stem cells, respectively. Stem Cells. 2009; 27:25712579. [PubMed: 19676123]

Miyaki M, Konishi M, Kikuchi-Yanoshita R, Enomoto M, Igari T, Tanaka K, Muraoka M, Takahashi H, Amada Y, Fukayama M, et al. Characteristics of somatic mutation of the adenomatous polyposis coli gene in colorectal tumors. Cancer Res. 1994; 54:3011-3020. [PubMed: 8187091]

Muncan V, Sansom OJ, Tertoolen L, Phesse TJ, Begthel H, Sancho E, Cole AM, Gregorieff A, de Alboran IM, Clevers H, Clarke AR. Rapid loss of intestinal crypts upon conditional deletion of the Wnt/Tcf-4 target gene c-Myc. Mol Cell Biol. 2006; 26:8418-8426. [PubMed: 16954380]

Nakamura M, Okano H, Blendy JA, Montell C. Musashi, a neural RNA-binding protein required for Drosophila adult external sensory organ development. Neuron. 1994; 13:67-81. [PubMed: 8043282]

Novelli MR, Williamson JA, Tomlinson IP, Elia G, Hodgson SV, Talbot IC, Bodmer WF, Wright NA. Polyclonal origin of colonic adenomas in an XO/XY patient with FAP. Science. 1996; 272:11871190. [PubMed: 8638166]

O'Brien CA, Pollett A, Gallinger S, Dick JE. A human colon cancer cell capable of initiating tumour growth in immunodeficient mice. Nature. 2007; 445:106-110. [PubMed: 17122772]

Ohlstein B, Spradling A. Multipotent Drosophila intestinal stem cells specify daughter cell fates by differential notch signaling. Science. 2007; 315:988-992. [PubMed: 17303754]

Ootani A, Li X, Sangiorgi E, Ho QT, Ueno H, Toda S, Sugihara H, Fujimoto K, Weissman IL, Capecchi MR, Kuo CJ. Sustained in vitro intestinal epithelial culture within a Wnt-dependent stem cell niche. Nat Med. 2009; 15:701-706. [PubMed: 19398967]

Pinto D, Gregorieff A, Begthel H, Clevers H. Canonical Wnt signals are essential for homeostasis of the intestinal epithelium. Genes Dev. 2003; 17:1709-1713. [PubMed: 12865297]

Potten CS, Booth C, Tudor GL, Booth D, Brady G, Hurley P, Ashton G, Clarke R, Sakakibara S, Okano H. Identification of a putative intestinal stem cell and early lineage marker; musashi-1. Differentiation. 2003; 71:28-41. [PubMed: 12558601]

Potten CS, Loeffler M. Stem cells: attributes, cycles, spirals, pitfalls and uncertainties. Lessons for and from the crypt. Development. 1990; 110:1001-1020. [PubMed: 2100251]

Potten CS, Owen G, Booth D. Intestinal stem cells protect their genome by selective segregation of template DNA strands. J Cell Sci. 2002; 115:2381-2388. [PubMed: 12006622]

Ramalho-Santos M, Melton DA, McMahon AP. Hedgehog signals regulate multiple aspects of gastrointestinal development. Development. 2000; 127:2763-2772. [PubMed: 10821773]

Ricci-Vitiani L, Lombardi DG, Pilozzi E, Biffoni M, Todaro M, Peschle C, De Maria R. Identification and expansion of human colon-cancer-initiating cells. Nature. 2007; 445:111-115. [PubMed: 17122771]

Roberts RB, Min L, Washington MK, Olsen SJ, Settle SH, Coffey RJ, Threadgill DW. Importance of epidermal growth factor receptor signaling in establishment of adenomas and maintenance of carcinomas during intestinal tumorigenesis. Proc Natl Acad Sci U S A. 2002; 99:1521-1526. [PubMed: 11818567]

Sangiorgi E, Capecchi MR. Bmi1 is expressed in vivo in intestinal stem cells. Nat Genet. 2008; 40:915-920. [PubMed: 18536716]

Sato T, Vries RG, Snippert HJ, van de Wetering M, Barker N, Stange DE, van Es JH, Abo A, Kujala P, Peters PJ, Clevers H. Single Lgr5 stem cells build crypt-villus structures in vitro without a mesenchymal niche. Nature. 2009; 459:262-265. [PubMed: 19329995]

Schmidt GH, Winton DJ, Ponder BA. Development of the pattern of cell renewal in the crypt-villus unit of chimaeric mouse small intestine. Development. 1988; 103:785-790. [PubMed: 3248525]

Schofield R. The relationship between the spleen colony-forming cell and the haemopoietic stem cell. Blood Cells. 1978; 4:7-25. [PubMed: 747780]

Scoville DH, Sato T, He XC, Li L. Current view: intestinal stem cells and signaling. Gastroenterology. 2008; 134:849-864. [PubMed: 18325394]

Shroyer NF, Helmrath MA, Wang VY, Antalffy B, Henning SJ, Zoghbi HY. Intestine-specific ablation of mouse atonal homolog 1 (Math1) reveals a role in cellular homeostasis. Gastroenterology. 2007; 132:2478-2488. [PubMed: 17570220] 
Smith KJ, Johnson KA, Bryan TM, Hill DE, Markowitz S, Willson JK, Paraskeva C, Petersen GM, Hamilton SR, Vogelstein B, et al. The APC gene product in normal and tumor cells. Proc Natl Acad Sci U S A. 1993; 90:2846-2850. [PubMed: 8385345]

Threadgill DW, Dlugosz AA, Hansen LA, Tennenbaum T, Lichti U, Yee D, LaMantia C, Mourton T, Herrup K, Harris RC, et al. Targeted disruption of mouse EGF receptor: effect of genetic background on mutant phenotype. Science. 1995; 269:230-234. [PubMed: 7618084]

Tumbar T, Guasch G, Greco V, Blanpain C, Lowry WE, Rendl M, Fuchs E. Defining the epithelial stem cell niche in skin. Science. 2004; 303:359-363. [PubMed: 14671312]

van den Brink GR. Linking pathways in colorectal cancer. Nat Genet. 2004; 36:1038-1039. [PubMed: 15454939]

van der Flier LG, van Gijn ME, Hatzis P, Kujala P, Haegebarth A, Stange DE, Begthel H, van den Born M, Guryev V, Oving I, et al. Transcription factor achaete scute-like 2 controls intestinal stem cell fate. Cell. 2009; 136:903-912. [PubMed: 19269367]

van Es JH, van Gijn ME, Riccio O, van den Born M, Vooijs M, Begthel H, Cozijnsen M, Robine S, Winton DJ, Radtke F, Clevers H. Notch/gamma-secretase inhibition turns proliferative cells in intestinal crypts and adenomas into goblet cells. Nature. 2005; 435:959-963. [PubMed: 15959515]

Velcich A, Yang W, Heyer J, Fragale A, Nicholas C, Viani S, Kucherlapati R, Lipkin M, Yang K, Augenlicht L. Colorectal cancer in mice genetically deficient in the mucin Muc2. Science. 2002; 295:1726-1729. [PubMed: 11872843]

Waghmare SK, Bansal R, Lee J, Zhang YV, McDermitt DJ, Tumbar T. Quantitative proliferation dynamics and random chromosome segregation of hair follicle stem cells. Embo J. 2008; 27:13091320. [PubMed: 18401343]

Wilson A, Laurenti E, Oser G, van der Wath RC, Blanco-Bose W, Jaworski M, Offner S, Dunant CF, Eshkind L, Bockamp E, et al. Hematopoietic stem cells reversibly switch from dormancy to selfrenewal during homeostasis and repair. Cell. 2008; 135:1118-1129. [PubMed: 19062086]

Yang Q, Bermingham NA, Finegold MJ, Zoghbi HY. Requirement of Math1 for secretory cell lineage commitment in the mouse intestine. Science. 2001; 294:2155-2158. [PubMed: 11739954]

Zhang YV, Cheong J, Ciapurin N, McDermitt DJ, Tumbar T. Distinct self-renewal and differentiation phases in the niche of infrequently dividing hair follicle stem cells. Cell Stem Cell. 2009; 5:267278. [PubMed: 19664980] 